
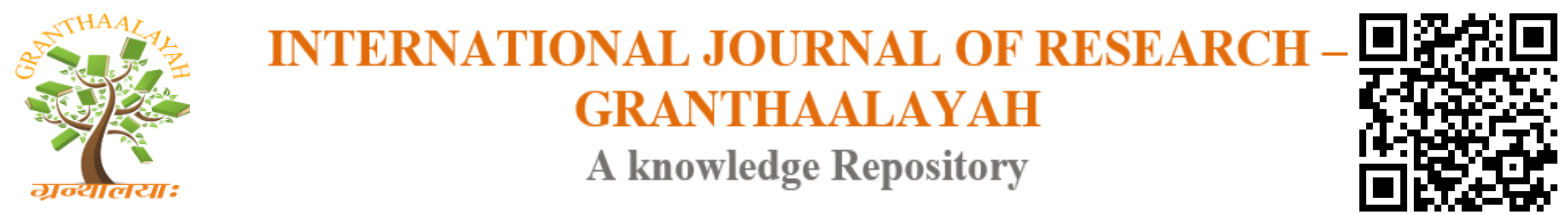

Science

\title{
STUDENTS' DIFFICULTIES AND MISCONCEPTIONS OF THE FUNCTION CONCEPT
}

\author{
Ashebir Sidelil Sebsibe ${ }^{* 1}$, Bereket Telemos Dorra ${ }^{2}$, Bude Wako Beressa ${ }^{3}$ \\ ${ }^{1,2}$ Department of Mathematics, Wachemo University, Ethiopia \\ ${ }^{3}$ Department of Mathematics, Wolaita Sodo University, Ethiopia
}

\begin{abstract}
This study explores understanding of function concept amongst 310 grade 11 science stream students in one administrative zone of Ethiopia. A test that included tasks given in different representations, about definition, about examples of functions in word description and applications of properties of functions was administered. Lesson observation and interview was also used for triangulation. Results have shown that limited mental image of approach to functions, fragmented conceptions and dependence on ordered pairs, limitation in algebraic manipulation, limitation on converting word expression into mathematical expressions, confusing combination and composition, unnecessary interchanging order of operations during algebraic manipulations and drawing graph without considering sufficient points were observed difficulties. Whereas, a relation is a function if it has algebraic expression, overgeneralization that a representation is a functions if it is symbolized as an ordered pairs, and considering every point of discontinuity as an asymptote were identified misconceptions. Thus, special attention should be given in the teaching-learning to overcome identified difficulties and misconceptions.
\end{abstract}

Keywords: Concept Definition; Concept Image; Difficulty; Function; Misconception; Representation.

Cite This Article: Ashebir Sidelil Sebsibe, Bereket Telemos Dorra, and Bude Wako Beressa. (2019). "STUDENTS' DIFFICULTIES AND MISCONCEPTIONS OF THE FUNCTION CONCEPT." International Journal of Research - Granthaalayah, 7(8), 181-196. https://doi.org/10.29121/granthaalayah.v7.i8.2019.656.

\section{Introduction}

The function concept is one of the vital concepts in mathematics which is taught from elementary to advanced level (Carlson \& Oehrtman, 2005). Due to its significance to the learning and understanding of further mathematics, it is able to get major attention from research community in mathematics education (Carlson \& Oehrtman, 2005; Hansson, 2006).

According to Carlson and Oehrtman (2005), good understanding and background of the function concept is fundamental not only for mathematics but also in sciences, engineering and technology 
fields of study. A deep and adaptable knowledge of the function concept is essential pre-request to be successful in calculus, which in turn is a vital to be successful in most undergraduate fields in natural science, engineers, technology and business (ibid). The other importance of the functions concept is also apparent in the course of its large connection with other mathematics concepts (Hansson, 2006). Thus, developing an understanding of the concept should have to include a comprehension of its relations and connection with the other concepts.

Even though the function concept has such importance in the teaching-learning of mathematics, there are many challenges in students to understand this concept. Research in different context of teaching-learning revealed that good number of students do not gain the required and matured understanding of this basic concept (Nguyen \& Tran, 2014). Students develop a range of difficulties and beliefs that vary from interpretation of symbolic notions to conflicts stemming from the representation of functions (Thomas, 2008).

From constructivist learning theory point of view, understanding of a concept is based on prior experience. Besides, in every discipline concepts are basis for further learning and development of a subject. This particularly is true of mathematics for it is highly sequential by its nature. The understanding of subsequent concepts is hardly possible if pre-requisite concepts are not clearly established. For example, a student cannot understand the concept of rational function before understanding the concept of rational numbers. Similarly, it is hardly possible to understand the concept of limit, which is the most fundamental concept in calculus, before clearly understanding the concept of function which is a necessary condition for understanding derivatives.

The general objective of the study is to examine grade 11 students' difficulties and misconceptions in learning mathematical function concepts in one administrative zone of Ethiopia.

Specifically, the study has the following objectives (I) investigate students' difficulties and challenges in understand mathematical function concept, (II) identify common misconceptions that students form in coming to understand mathematical function concept.

\section{Review of Related Literature}

This study is an attempt to examine students understanding of the function concept vis-a- vis analyzing their ability to apply and the extent they make connection among different forms of representations of the notions, their mental image on examples and non-examples of function, and their ability to apply properties of functions on given tasks. Having a constructivist theoretical viewpoint of learning, the focus of attention is how do students' construct meaning and understanding of mathematical concepts based on their prior experience and current learning context. According to Elia and Spyrou (2006, p.256) understanding of the function concept incorporates the following three fundamental components: "defining the concept, giving examples of the application of the concept in everyday life, identifying functions in different modes of representation, and changing systems of representation". In this section of the study, review of the key terms of the study i.e. concept image and concept definition, representation, and misconception were presented. 


\subsection{Concept Image and Concept Definition}

Concept image and concept definition are terms associated with most studies in conceptual understanding of a topic in mathematics. Accordingly, concept image is all cognitive structure that students build for each mathematical concept (Tall \& Vinner, 1981). On the other hand, concept definition is a proper definition of the concept (given by the scientific community and available on school resources). In short, it is a form of words that specific the given concept. Tall and Vinner (1981, p. 152) explain concept image as "the total cognitive structure (in an individual's mind) that is associated with specific mathematical concept". It consists of all cognitive structural pieces and related properties and processes of a concept that a learner made through her/his meet with the concept. It is not one time construct, but matures over time through all kinds of exposure and modifies as the individual assemble new experience. The construction is also individual and every student has his/ her own distinctive concept image. So, an individual may invent concept definition to describe his/her concept image. Therefore, an individual concept image of a given concept may much or mismatches its concept definition.

According to Vinner (1983), all mathematical concepts apart from postulates and axioms have proper definitions. Students introduced to these definitions in the meantime of their school years. But they does not essentially use these definitions when dealing whether a given mathematical concept to solve a given exercise or problem. Usually, she/he reacts based on her/his concept image. The student's concept image is a product of her/his experiences with examples and nonexamples of the notion. Consequently, a mathematical object recognize as an examples of the given concept by the student may not be essentially the same as that settle on the concept definition. Whenever these two constructs are different, what student's performance possibly will differ or deviate from what a teacher wait for.

Cornu (2002) has studied the implications of the mismatch between this concept image and concept definition for the learning process; by saying students face difficulty because of the concept image is incomplete or is insufficient to deal with a given incident. In other words, the student has a point of view (due to their cognitive construct) that is too narrow, too exclusive, and thus inappropriate for dealing with a given situation or for solving a given problem. When there is such a mismatch of concept image and concept definition, students not only face difficulty in their current situation but also on their further learning of the concept or solving problems. This can be observed in students' verbal or written task (homework, assignment or class activity). Recognizing topics of difficulty in which students demonstrate systematic and persistent errors and designing alternative approach to enhance understand supposed to be a major focuses of attention of teachers at each level of teaching mathematics (Drlik, 2015).

\subsection{Representations in Learning the Function Concept}

Thomas (2008) expressed the importance of representation in mathematics as much of mathematics is about what we can learn about concepts through their representations or signs. The function concept usually introduced as a special type of relation using numerous form of representations- ordered pairs, Venn diagrams, tables, graphs, algebraic descriptions or word expressions. All these approaches to introduce the concept have both positive and negative consequence on students understanding of the concept depending on students learning style 
preferences. For instance, the ordered pairs approach is pedagogically the weakest and nonintuitive which appeal to all kinds of logistic and epistemological problems (Eisenberg, 1991). Usually, students lack to make the connection that all representations communicate the same information in different forms. Supporting this, Sierpinska (1992) mentioned that students have difficulties not only in recognizing relations among various representations of the same concept but also in interpreting representations and operate symbols related to functions. Lambertus (2007) seems more aware to the difficulty of making connection among these representations. She state that "making connections between the representations leads a student who can claim a circle is function because it has a mathematical name in the verbal or symbolic representations and then can look at the graph of a circle and claim that it is not a function because the graph does not extend toward infinity or pass the vertical line test" (p.14).

Most studies in the topic of representation are associated with the theme "compartmentalization" in teaching. Teachers approach which characterized as compartmentalization discloses a cognitive difficulty that occurs from lack of making association and bring about flexible of conversion back and forth among various mathematical representations of the same concept (Duval, 2002; Elia \& Spyrou, 2006), which according to Thomas (2008) is the central part of mathematical learning.

To introduce a concept teacher, use representations. To represent a concept involves producing an illustration, example (non-example) or mental image of it (Dreyfus, 1991). The subsequent learning of a student largely depends upon this mental image and the learning context (mainly, the teachers' approach and nature of activities provided). Based on this exposure, students' notion of a function may be develop to actions to be interiorized, process to be encapsulated or as an object to be manipulated both as process and concept (Cottrill et al., 1999). The key component in learning of a mathematics concept is related to the encapsulation of processes into objects (Sfard, 1991).

\subsection{Misconceptions}

Misconception happens when there is mismatch of concept image and concept definition or different concept image of the same concept co-exists. For example, students may not fully comprehend the concept definition of function. So, they form their own concept image which is either partially or totally different from the formal definition. This lack of understanding the definition leads in one or another time causes contradiction in students' mental structure of the concept (DeMarois, 1996; Slavit, 1997; Vinner \& Dreyfus, 1989). At their early exposure to the definition, students are usually establish to a formal definition of function "correspondence between two non-empty sets that assigns to every element in the first set (the domain) exactly one element in the second set (the co-domain)" (Vinner \& Dreyfus, 1989, p.357). This definition is not only one of its kinds. An investigation of mathematics textbook exposed several of such definitions for the function concept. Lambertus (2007, p. 28) summarized definitions for function found in texts as follows:

- a function is a relation in which no two different ordered pairs have the same first coordinate;

- a variable $y$ is a function of a variable $x$ if each value of $x$ determines a unique value for $y$;

- a function is a relation that pairs each element in a domain $D$ with exactly one element in a range $R$; 
- a function is a correspondence between a first set, called the domain, and a second set, called the range, such that each member of the domain corresponds to exactly one member of the range;

- a function is a correspondence that matches each input value with exactly one value of the output variable.

Whichever definition is used, the students take action based on their concept image and it is not obligatory to use the formal definition. Once introduced the definition, the teacher continue the lessons via illustration, examples and non-examples to assist the students understanding. All these efforts assist students to strength their concept images and as a result, they react based on this concept images whenever necessary. This involves learner's internal construction and sense making of their natural thoughts and experiences. This actively creation of concept image or mental construction of knowledge out of experiences is fully individual (and influenced by the context). Whatever the depth and breadth, there will be a concept image. The maturity of this concept image depends on their own experience, the nature of examples, assessments, and worksheets provided by the teacher and the nature of text and reference books and so on.

When students perform a task, they usually make two types of errors. The first types are neither conception nor the result of conception, rather result of processing and are simple and quick to overcome them (Amatangelo, 2013). The second are result of reasoning on the part of the learner. These types of errors which are result of reasoning, and that will happen repeatedly when the individual is in particular situations, are indications of alternative conceptions or misconceptions. Thus, misconceptions are underlying conceptual structures which cause errors which in turn lead to wrong conclusion during problem solving (Amatangelo, 2013).

Misconceptions can be detected from learners' response to test items or class activity and if well managed in order to reconcile results success in learning otherwise can be an obstacle and causes dissatisfaction. Although it is not possible to prevent misconception from arising, considerable efforts must be applied to overcome or reduce them.

\section{Materials and Methods}

The stated research questions of this study are empirical data demanding. Hence, both qualitative and quantitative approaches particularly descriptive survey method have been employed on the ground that it is found to be helpful to obtain relevant information on the actual issue under study. The quantitative approach is meant for quantifying data generated in terms of frequency and percentage, while qualitative approach is used to provide detailed description of the data to help the researchers explore and distinguish inherent information.

Sampling: The sample frames of this study were eleven preparatory schools in the Zone. In the eleven schools there were a total of 2670 grade 11 science stream students. The schools had used as strata so as to determine the sample that were taken from each school. The sample size for the test was determined using random samples table (Cohen, et al., 2007). Accordingly, 333 students were selected. After careful diagnosis of the test script, 310 of them were selected for the analysis. 
Data collection instrument: Students' achievement test was the major data collection instrument. Test items of both closed ended and open ended were prepared. The closed ended respond was made to identify areas of misconception while the free respond was meant to investigate in depth analysis skill of student understanding the function concept. Taking in to account the purpose of the test, most items were taken from previous studies in the field (internet source) and some others prepared by the researchers. After the items were selected and prepared, modifications were made based on evaluation held by panel of experts and pilot test. In addition, classroom observation and students' interview were used for triangulation purpose. Based on information from students' test script, eighteen students were selected and Semi-structured interview were carried out.

Data analysis: To analyze the test result, first subjects' scripts for each item were categorized as correct, incorrect and no response. The number of students in each category for every item was quantitatively described using percentage. Second for each item the subjects' script were identified and analyzed by looking for the wrong choice, wrong working or strength in justification. Since these wrong answers constitute way of conception, misconception and origins of misconceptions that they have. The data were read over and over again to get an overall picture to the type of responses that the subjects were given to examine the conceptions and misconceptions. The test result together with result from the actual classroom observation and student interview were used to draw conclusion.

\section{Result and Discussion}

The analysis proceeds in the order of the items in the test i.e. representations (4.1), definition and examples of function versus non-function (4.2), properties of functions (4.3) followed by graph of functions (4.4). Where relevant, interview and classroom observation extracts were also included to support the discussion.

\subsection{Students Understanding of the Function Concept in Different Representations}

Item 1.1 and 1.2 were aimed to test students' conception of function using ordered pairs. Item 1.1 represent a function were as item 1.2 does not. Almost $80 \%$ of them responded to both items correctly. Though the items were closed ended, students were asked to write their reason of choice. Some of the correct justifications from students' scripts are the following (table 1 presents summary of response to item 1):

Table 1: Summary of students' response to item 1

\begin{tabular}{|l|c|c|c|c|c|c|c|c|}
\hline \multirow{2}{*}{ Item number } & \multicolumn{9}{|c|}{ Alternative } & \multicolumn{2}{c|}{ Total } \\
\cline { 2 - 9 } & \multicolumn{2}{|c|}{ Correct } & \multicolumn{2}{|c|}{ Incorrect } & Non-respondent & \multicolumn{2}{c|}{} \\
\cline { 2 - 9 } & $\mathbf{N}$ & $\mathbf{\%}$ & $\mathbf{N}$ & $\mathbf{\%}$ & $\mathbf{N}$ & $\mathbf{\%}$ & $\mathbf{N}$ & $\mathbf{\%}$ \\
\hline 1.1 & 251 & 80.9 & 50 & 16.1 & 9 & 2.9 & 310 & 100 \\
\hline 1.2 & 242 & 78 & 59 & 19 & 9 & 2.9 & 310 & 100 \\
\hline 1.3 & 246 & 79.4 & 44 & 14.2 & 20 & 6.4 & 310 & 100 \\
\hline 1.4 & 221 & 71.2 & 80 & 25.8 & 9 & 2.9 & 310 & 100 \\
\hline 1.5 & 230 & 74.1 & 66 & 21.3 & 14 & 4.5 & 310 & 100 \\
\hline 1.6 & 155 & 50.0 & 135 & 43.5 & 20 & 6.4 & 310 & 100 \\
\hline 1.7 & 190 & 61.3 & 109 & 35.1 & 11 & 3.6 & 310 & 100 \\
\hline
\end{tabular}


$\mathrm{G}_{04}$ : because the given ordered pair is the type of many to one order pairs and the $1^{\text {st }}$ items is not paired with two $2^{\text {nd }}$ items.

: because the $1^{\text {st }}$ item (2) is paired with two $2^{\text {nd }}$ items, it is one -to - many. It is not allowed. $\mathrm{F}_{10}$ : because $\mathrm{x}$ is not repeated.

: because $\mathrm{x}$ is repeated.

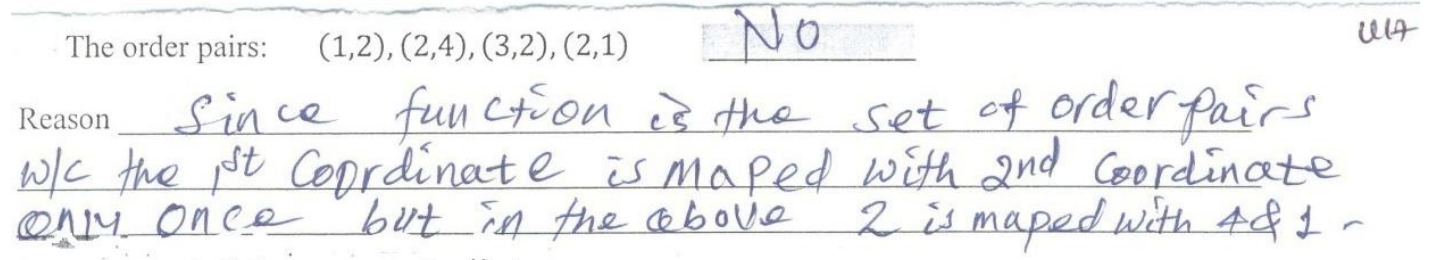

Figure 1: Student $U_{17}$ evidence of reasoning style

Accordingly, the reason given to their answers was based on inspection of the domain (whether a domain element is mapped to more than one range element or not). Figure 1 is an evidence of this reasoning style from one student's test script. This kind of conception agrees with definition on students' text and the one given by Bello (1998, p.124) "A function is a relation in which no two different ordered pairs have the same first coordinate".

Thus, students are successful in differentiating whether a representation is a function or not given in ordered pairs but a good number of them also developed overgeneralization that all functions have to be represented as ordered pairs. This result agrees with what Lambertus (2007) concerned about Bello's chose to define a function in terms of ordered pairs when she state that it may lead to think that all functions have to be represented as ordered pairs.

Item 1.3 and 1.4 were aimed to test students' conception of function using Venn diagram. Item 1.3 does not represent a function were as item 1.4 does. As the data in table one reveled, $79.4 \%$ of them responded to the former correctly, whereas $71.2 \%$ of them responded correctly to the later. Still by inspection of the domain is the reason mentioned as justification to their decisions.

The third category, item $1.5,1.6 \& 1.7$ were aimed to test students' conception of function using algebraic expression. The first two does represent a function were as the third does not. Accordingly, $74.1 \%, 50 \%$ and $61.3 \%$ of them responded correctly to the three items respectively. From the reasons given to their response, it is observed that even those who responded correctly have provided wrong justifications. Some of the responses from students' scripts are the following: $\mathrm{G}_{34}$ : yes, it is one to one function, when we test in the horizontal line it cross only one time.

: yes, it is many to one.

: no, because for negative values of $x$ it has no $y$ value $b / c$ in the radical -ve numbers didn't exist. $\mathrm{U}_{18}$ : yes, since linear equations are functions

: (not answered)

: not, for one member of $x$, there is two members of $y$-value due to these reason it is not function. 
Figure 2 present student $\mathrm{G}_{01}$ evidence of reasoning base on vertical line test

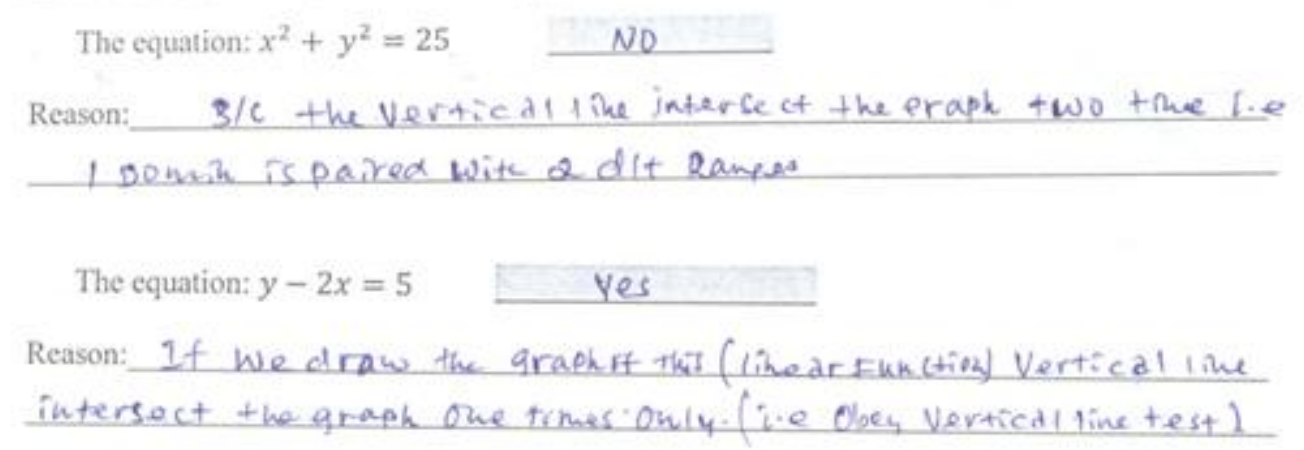

Figure 2: Student $\mathrm{G}_{01}$ evidence of reasoning base on vertical line test

Difficulties observed from subjects' were summarized as follows: the believe that linear and quadratic equations are functions; equations in explicit form are functions; if the domain and range (input-output) are all real numbers then it represent a function; difficulty of recognize function of more than one formula; instead of justifying, replacing constants for the variables or giving examples of similar equation that they know.

Conception that was observed during interview was that a necessary condition to be a function is to contain two variables (particularly, $x$ and $y$ ) and a good number of them have confused to determine linear equations of one variable as a function, whether the variable is x or y; particularly, $y=a$ (constant function, for instance, $\mathrm{y}=3$ ). Of course this is not well covered in algebraic form in students textbook but there are some graphs of this nature. With this regard, those who use the vertical line test were more successful.

In general, students' conception of function concept is more of ordered pairs than others. Even to decide the representation given in Venn diagram and equation, students prefer to make ordered pairs and see the frequency of the first order pair. Though good number of subjects' conception agrees with the formal definition on their text, they were not seen to mention or refer the definition as a justification. This may be the tendency of teachers rely more on counter examples to introduce the concept of functions, as witnessed during the classroom observation.

Thus, from all the above facts, it is possible to draw the conclusion that most students have no flexibility in their approaches to function representation; rather a univalent dependence on ordered pairs, and limited mental image of function representation are observed difficulty of students. Overgeneralization that all functions have to be represented as ordered pairs and piecewise function is actually distinct functions are also observed.

\subsection{Students' Definition and Examples for What A Function is}

Definitions and examples given by students expose their concept image. Content analysis of the definition or examples can imply students' difficulties or misconceptions. Function is defined in Ethiopian grade 11 text books as follows " $A$ function is a relation in which no two distinct ordered pairs have the same first element. A function is a relation in which no two of the ordered pairs in it have the same first element" (p. 9, 35)". The aim of item number 2.1 was to examine how students define a function. Table 2 presents summary of response to item 2 . 
Table 2: Summary of students' response to item 2

\begin{tabular}{|l|c|c|c|c|c|c|c|c|}
\hline \multirow{2}{*}{ Item number } & \multicolumn{6}{|c|}{ Alternative } & \multicolumn{2}{c|}{ Total } \\
\cline { 2 - 9 } & \multicolumn{2}{|c|}{ Correct } & \multicolumn{2}{|c|}{ Incorrect } & Non-respondent & \multicolumn{2}{c|}{} \\
\cline { 2 - 9 } & $\mathbf{N}$ & $\mathbf{\%}$ & $\mathbf{N}$ & $\mathbf{\%}$ & $\mathbf{N}$ & $\mathbf{\%}$ & $\mathbf{N}$ & $\%$ \\
\hline 2.1 & 130 & 41.9 & 153 & 49.4 & 27 & 8.7 & 310 & 100 \\
\hline 2.2 & 93 & 30.0 & 181 & 58.4 & 36 & 11.6 & 310 & 100 \\
\hline 2.3 & 90 & 29.0 & 164 & 52.9 & 56 & 18.1 & 310 & 100 \\
\hline 2.4 & 234 & 75.5 & 69 & 22.3 & 7 & 2.2 & 310 & 100 \\
\hline
\end{tabular}

According to the data in table $2,91.3 \%$ of respondents try to answer item 2.1 . But only $41.9 \%$ of them succeeded in doing so. The remaining, instead of answering as per requested, they tried to do one of the following: provided an example (of course some of them are not correct); wrote properties or categories of functions; wrote incomplete statement. Accordingly, some counter cases are the following: $\mathrm{x}$ is a father of $\mathrm{y}$; all functions are relations but all relations are not functions; a relation of variables and numbers; a set of ordered pairs; one to one or onto functions; function is the set of ordered pairs; function is a relation with different first coordinate. Figure 3 is an evidence of students' definition taken from their test script.
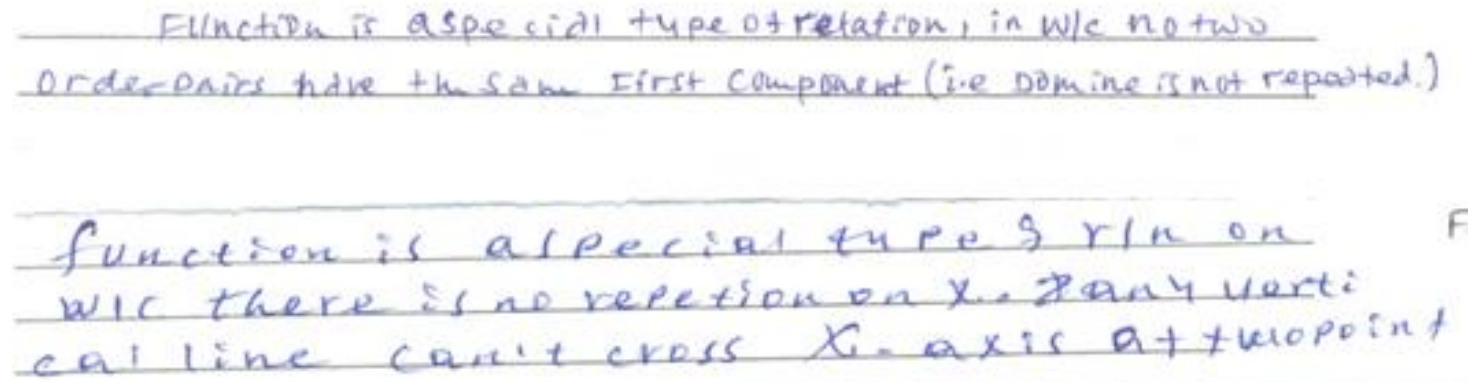

Figure 3: An evidence of students function definition

Thus, confusing definition, example, and properties of a concept is observed difficulty. This is may be due to availability of fragmented concept image.

Item 2.2 and 2.3 were elementary but unusual to students' exposure. Both items represent a function. As shown in table 2, besides less correct response, this category has immense nonresponse rate. This reveals that students' depth of understanding is not enough to extend to nonfamiliar exercise. As witnessed from classroom observation and students text book students have no exposure to such kind of items. Only $30 \%$ and $29 \%$ of students responded correctly to the items respectively. Even those who responded correctly have limited to give justification to their argument. Justifications both from correct and non-correct respondents are summarized as follows: the inputs are not the same as the outputs, domain (first digit or order pair) is repeated, a letter cannot be a domain or letters cannot be mapped to a numbers, there is no equation to represent this relation. 
Among subjects, who said item 2.3 is not a function, were interviewed and one of them is presented as follows:

$\mathrm{R}: \operatorname{does}\{(m, 2),(a, 2),(t, 2),(h, 1),(e, 1),(i, 1),(c, 1),(s, 1)\}$ represent a function?

$\mathrm{W}_{23}$ : yes (after doing some mapping)

$\mathrm{R}$ : but you said this is not a function (showing him item 2.3 on the test paper)

$\mathrm{W}_{23}$ : that is different from this.

$\mathrm{R}$ : are you sure?

$\mathrm{W}_{23}$ : I think so.

R: let us do it together. Take one word (moment of silence). Let us take 'mathematics', then accordingly, we map, how many $m$ we have...

$\mathrm{W}_{23}$ : yes, really it works (it is convinced that the example given here is the same as the item on the test paper).

Thus, besides the tendency to rely on ordered pairs approach, one difficulty is conversion of the word expression into mathematical expression.

Item 2.4 were aimed to examine whether students can construct or give example of a function from their own and if so, to examine the distinctiveness of the examples. Shown in table 2, this item is unique in that it has high respondent rate. Of course, $75.5 \%$ of them were correct answers. But the nature of the examples revealed that students' concept image of what a function is very narrow. Accordingly, the total 313 examples mentioned by respondents, have the following categories and distributions. Table 3 is summary of students' examples of function in four categories.

Table 3: Summary of students' examples of function

\begin{tabular}{|l|c|l|}
\hline Representation & Frequency & Remark \\
\hline ordered pairs & 134 & order pair of integers, integers and letters \\
\hline algebraic expressions & 115 & most of them polynomials (linear) \\
\hline Venn diagram & 37 & of integers, integers and letters \\
\hline word expressions & 27 & most of them were of the form "y is father of x" \\
\hline
\end{tabular}

Only three students gave a different example (the sigma (Weierstrass sigma) and the greatest integer functions, power and exponential functions). There are also respondents who tried to write definition of function, properties of functions, type and categories of functions instead of giving a specified example as requested. Figure 4 is evidence from two students' scripts about examples of function.

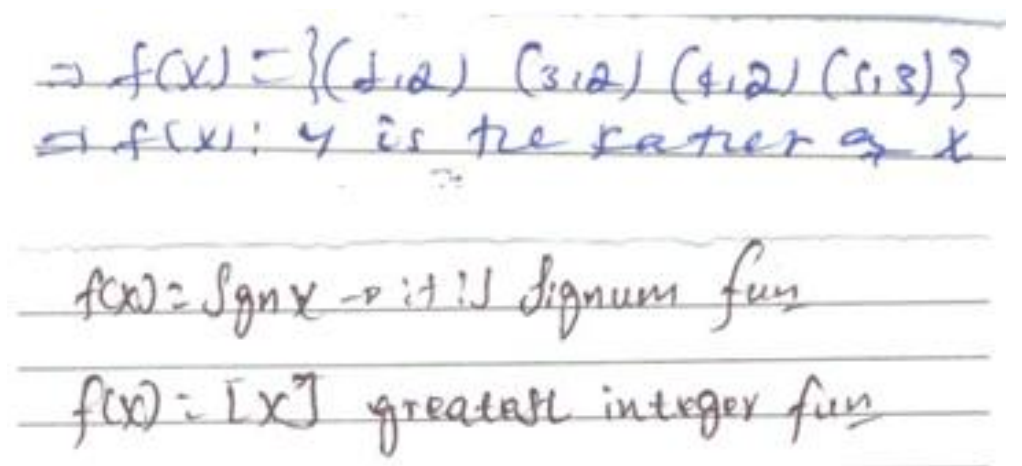

Figure 4: Two students' ( $\left.\mathrm{W}_{16} \& \mathrm{~F}_{19}\right)$ scripts about examples of function 
The result of item 2 revealed that most students concept image of function was not matured enough to described in the form of words, extended to unfamiliar contexts, and to provide variety of examples. This reveals not a mere language problem, rather level of conceptual knowledge (an unmatured concept image and fragmented conception). According to Vinner and Dreyfus (1989) in most cases students decides on the basis of a concept image. Thus, students' un-matured concept image of function is one cause of students' confusing definition, properties, types and examples of functions.

\subsection{Students' Knowledge of Using Different Properties of Function}

Item 3 was aimed to explore students' procedural and conceptual understanding. Item 3.1 require simple computation of composition of two functions in algebraic description whereas item 3.2 and 3.3 using non-algebraic description. On the other hand Item 3.4 require reversing this action i.e. given a composition and one of the individual function, then to extract the other from the compound function. Table 4 presents summary of response to item 3.

Table 4: Summary of Students' Response to Item Number 3

\begin{tabular}{|l|c|c|c|c|c|c|c|c|}
\hline \multirow{3}{*}{ Item number } & \multicolumn{6}{|c|}{ Alternative } & \multicolumn{2}{c|}{ Total } \\
\cline { 2 - 9 } & \multicolumn{2}{|c|}{ Correct } & \multicolumn{1}{c|}{ Incorrect } & Non-respondent & \multicolumn{2}{c|}{} \\
\cline { 2 - 9 } & $\mathbf{N}$ & $\mathbf{\%}$ & $\mathbf{N}$ & $\mathbf{\%}$ & $\mathbf{N}$ & $\mathbf{\%}$ & $\mathbf{N}$ & \% \\
\hline 3.1 & 173 & 55.8 & 119 & 38.4 & 18 & 5.8 & 310 & 100 \\
\hline 3.2 & 104 & 33.5 & 152 & 49.0 & 54 & 17.4 & 310 & 100 \\
\hline 3.3 & 98 & 31.6 & 118 & 38.0 & 94 & 30.3 & 310 & 100 \\
\hline 3.4 & 89 & 28.7 & 127 & 40.9 & 95 & 30.6 & 310 & 100 \\
\hline
\end{tabular}

Item 3.1 correctly answered by $173(55.8 \%)$ of subjects. The question asked was to find the composition, $f \circ g$ where $g(x)=(x+2)^{2}$ and $f(x)=\sqrt{x}$ and the correct procedure is:

$$
\begin{aligned}
(f \circ g)(x) & =f(g(x)) \\
& =f\left((x+2)^{2}\right)=\sqrt{(x+2)^{2}} \ldots \ldots * \\
& =|x+2| \ldots \ldots * *
\end{aligned}
$$

The following are direct copy of students' scripts:

$$
\begin{aligned}
& \mathrm{U}_{19}:(f \circ g)(x)=f(g(x))=f\left((x+2)^{2}\right)=(\sqrt{x+2})^{2}=x+2 \\
& \mathrm{G}_{11}:(f \circ g)(x)=f(g(x))=\sqrt{(x+2)^{2}}=x+2 \\
& \mathrm{~S}_{33}:(f \circ g)(x)=\sqrt{x}(x+2)^{2}=x(x+2)=x^{2}+2
\end{aligned}
$$

Some of observed difficulties are: confusing combination and composition, interchanging order of operations (good number of subjects make the square out of the radical), ignoring or omitting the absolute value, limited mental image of algebraic manipulation. Almost all those who are successful in the algebraic manipulation are also successful in identifying the domain of the composition function. 
The objective of Item 3.2 and item 3.3 were the same as item 3.1 but with a different representation. But there is a big difference on these who answered the former one and the latter two. Even good number of them did not consider them as a process to be performed. Item 3.4 is reversed process of composition. Surprisingly this item has less correct response rate and high non-respondent rate and good number of them were not justified their answer. It seems they have completely no idea. Thus, item 3 portrays, students understanding lack process level conception. The introductory part of function is dominated by ordered pair and mapping representation but then switched to algebraic expression. This led them to experience inconsistency of representations. This Students' difficulties of composing and decomposing of functions agree with the finding of Cottrill (1999).

\subsection{Students' Knowledge About Graph of Function}

The aim of item number 4 was to examine whether students are able to sketch graph of a function, the function being undefined at some point, how they deal a point at which the function is undefined. As the data in table 4, most students $(83.2 \%)$ of them tried to sketch the graph of $\mathrm{f}$ but only $30.6 \%$ of them were successful. Students difficulties observed from their script were include but not limited to the following: ignore the restriction on the domain after simplification or when joining points to construct the graph, do not consider $\frac{x+3}{3}$ as a polynomial, limited algebraic manipulation skill, drawing the graph without considering sufficient points which lie on the graph, considering every point of discontinuity as an asymptote. Table 5 presents summary of response to item 4.

Table 5: Summary of students' response to item 4

\begin{tabular}{|l|c|c|c|c|c|c|c|c|}
\hline \multirow{2}{*}{ Item number } & \multicolumn{6}{|c|}{ Alternative } & \multicolumn{2}{c|}{ Total } \\
\cline { 2 - 9 } & \multicolumn{2}{|c|}{ Correct } & \multicolumn{2}{|c|}{ Incorrect } & Non-respondent & \multicolumn{2}{c|}{} \\
\cline { 2 - 9 } & $\mathbf{N}$ & $\mathbf{\%}$ & $\mathbf{N}$ & $\mathbf{\%}$ & $\mathbf{N}$ & $\mathbf{\%}$ & $\mathbf{N}$ & $\%$ \\
\hline 4.1 & 95 & 30.6 & 163 & 52.6 & 52 & 16.8 & 310 & 100 \\
\hline 4.2 & 141 & 45.5 & 101 & 32.5 & 68 & 21.9 & 310 & 100 \\
\hline 4.3 & 95 & 30.6 & 135 & 43.5 & 79 & 25.5 & 310 & 100 \\
\hline 4.4 & 135 & 43.5 & 101 & 32.5 & 74 & 24 & 310 & 100 \\
\hline
\end{tabular}

These observed limitations affected the subsequent activities. It was observed that most of them tried to determine the domain and range from the graph. Since some of them use integers as counter examples to plot the graph, they conclude that the domain is integers. Examples of correct and incorrect graph respectively from their script are given in figure 5.
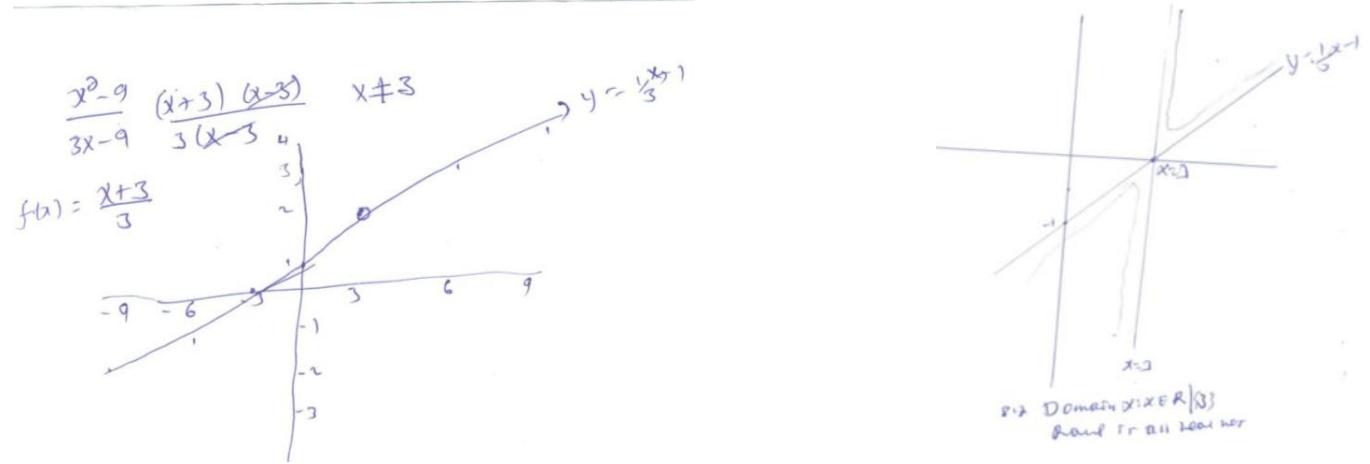

Figure 5: An illustration of correct and incorrect graph from two students test script. 
Item 4.3 and item 4.4 are the same concepts. But students understand the former quite differently. Referring to item 4.3 that 'what happens to the graph of $f$ at $\mathrm{x}=3$ ?' $30.6 \%$ of them were answered by saying that the graph makes a hole which is correct. Incorrect responses given were grouped as follows: it has an asymptote, it becomes zero, there is a gap, the graph will be continuous and the graph is at infinity.

On question 4.4 students were asked 'is the function (continuous/discontinuous) at the point $\mathrm{x}=3$ ?' Referring to table 5, 32.5\% of them said the graph is continuous at the point $x=3$. These may be lack of exposure to rational functions. Most of the students who answered discontinuous for item 4.4 are these who ignored the restriction on the domain after simplification. Thus, the students' response is a good indication of students' knowledge on function is short of depth. From the interview, it is understood that students consider hole and gap as the same concepts, and any point of discontinuity as an asymptote.

\section{Conclusions and Recommendations}

The basic goal of this study was to examine students' difficulties and common misconceptions in coming to understand the function concept. This study was carried out in a different context as compared to those of other research studies used in the literature. Accordingly, some of those studies were conducted in a computer assisted teaching-learning setting, in contexts where the native language was used as a medium of instruction and some were conducted in context where the researchers themselves were involved in the teaching of the subject matter and some studies were at undergraduate level. This study was conducted in a context where students have no experience of educational technology like graphic calculator or computer and almost all respondents at age 17 years. Besides these differences there are however, some similarities in the findings regardless of context.

Mostly students' difficulty arose from lack of forming connections among representations. At the introductory part the focus is 'ordered pairs'. Even the text book have examples of different representations and teachers also provide examples and non-examples using different representations, the classroom discussion and students reaction is based on the ordered pairs approach. After a while, the whole focus was shifted to algebraic expression. Thus, students think that the formal definition and the ordered pair's representation as a separate concept from the subsequent part of functions; which is algebraic expression dominated. Eisenberg (1991) seems more concerned about difficulty of focusing on ordered pair approach before two and half decades "of all these approaches the pedagogically weakest and non-intuitive one seems to be the approach using order pairs (p. 141)". But the main thing in mathematical knowledge is the ability to make like among the representations and flexibility to use whenever required. Thus, limited mental image of function representations and fragmented conceptions are observed difficulty of students whereas, overgeneralization that all functions have to be represented as an ordered pair is observed misconception.

Moreover, most students concept image of function was not matured enough to described in the form of words, to be generalized in to unfamiliar context and to provide variety of examples. There evoked concept image is that they formed at the introductory part of function. Cornu (2002) point out that such concept images turn out into difficulty when the student is faced with a situation 
where, because of its incompleteness, the concept image is insufficient. Furthermore, Students' concept image is largely limited to order pair, phrases like $\mathrm{y}$ is father of $\mathrm{x}$ and linear algebraic expressions of two variables; $x$ and $y$. This may be they work a long time with limited cases (ordered pairs, " $y$ is father of $x$ ", polynomial functions). The examples that students provided for the function concept were very elementary, narrow and lack verity. It is also found that besides the tendency to rely on ordered pairs approach, students have difficulty to convert word expression into mathematical expressions. This finding also agrees with previous research findings (e.g. Nguyen \& Tran, 2014).

The study also revealed that students have relatively better procedural skill of computing algebraic manipulation but difficulty of computing the reverse as well as when the representation is changed. Confusing combination and composition, interchanging order of operations and limited mental image of algebraic manipulation were observed difficulties.

If students understand a function as a set of ordered pairs, they understand a function as object. This understands a function as an object means to understand the definition of a set of ordered pairs without referring to variables (Sfard, 1991). Thus, they conceive as if the ordered pair is different from the algebraic expression, which involves variables. As a result, students understanding becomes fragmented, lack flexibility. The ability to understand a function as an object does not mean that students have no misconceptions about the function (ibid.). But the good opportunity is that such misconceptions are not robust to change as students with such have no ontological difference from experts' conceptions of the function or concept definition (ibid.).

Ignore restriction on the domain after simplification or when joining points to construct graph of a rational function and drawing the graph without considering sufficient points which lay on the graph are other difficulties that students encountered whereas considering every point of discontinuity as an asymptote is a misconception.

As it is understood from classroom observation, focus of the mathematics teachers practice is more of procedural computation than conceptual understanding; both in their lesson presentation and assessment. Whether one views mathematical concepts as a foundation for application or as a pure, procedures or techniques is necessary but not sufficient to the course. Thus, it is necessary to pay attention and teach the concepts in order to apply it.

\section{Acknowledgement}

The authors thankful to Wachemo University research and community service vice president office for providing found for the successful completion of this study.

\section{References}

[1] Amatangelo, M. L. (2013). Student Understanding of Limit and Continuity at a Point: A Look into Four Potentially Problematic Conceptions. Master's Thesis, Brighan Young University. Retrieved from http://scholarsarchive.byu.edu/etd

[2] Bello, I. (1998). Intermediate Algebra: A Graphing Approach. Tampa, FL: Brooks. Cole Publishing Company. 
[3] Carlson, M., \& Oehrtman, M. (2005). Key Aspects of Knowing and Learning the Concept of Function. Mathematical Association of America Research Sampler, (9). Retrieved from https://www.maa.org

[4] Clark, J. M., Cordero, F., Cottrill, J., Czarnocha, B., DeVries, D. J., John, D. S., \& Vidakovic, D. (1997). Constructing a Schema: The Case of the Chain Rule. The Journal of Mathematical Behavior. 16(4), 345-364.

[5] Cohen, L., Manion, L., \& Morrison, K. (2007). Research Methods in Education (6th Ed.). Routledge: New York.

[6] Cornu, B. (2002). Limit. In D. Tall (Ed.), Advanced Mathematical Thinking (11th ed., pp. 3-21). London: Kluwer Academic Publisher.

[7] Cottrill, J. (1999). Students' Understanding of the Concept of Chain Rule in First Year Calculus and the Relation to their Understanding of Composition of Functions. Doctoral Dissertation, Purdue University. Retrieved from http://homepages.ohiodominican.edu/ cottrilj/thesis.pdf

[8] Cottrill, J., Dubinsky, E., Nichols, D., Schwingendorf, K., Thomas, K., \& Vidakovic, D. (1996). Understanding the Limit Concept: Beginning with a Coordinated Process Scheme. Journal of Mathematical Behavior. 15(2), 167-192.

[9] DeMarois, P. (1996). Beginning Algebra Students' Images of the Function Concept. In On-Line Proceedings of the Twenty-Second Annual Conference of the American Mathematical Association of Two-Year Colleges. Retrieved from http://citeseerx.ist.psu.edu/viewdoc/download?doi=10.1.1.46.5260\&rep=rep1\&type $=$ pdf

[10] Dreyfus, T. (1991, June). On the status of visual reasoning in mathematics and mathematics education. In Proc. 15th Conf. of the Int. Group for the Psychology of Mathematics Education (Vol. 1, pp. 33-48). Retrieved from https://www.researchgate.net/publication/247047839

[11] Drlik, D. I. (2015). Student Understanding of Function and Success in Calculus. Master's Thesis. Boise State University. Retrieved from http://scholarworks.boisestate.edu/cgi/viewcontent.cgi?article=1935\&context=td

[12] Duval, R. (2002). The Cognitive Analysis of Problems of Comprehension in the Learning of Mathematics. Mediterranean Journal for Research in Mathematics Education. 1(2), 103-131.

[13] Eisenberg, T. (2002). Functions and Associated Learning Difficulties. In D. Tall (Ed.), Advanced mathematical thinking (11th ed., pp. 140-152). London: Kluwer Academic Publisher.

[14] Elia, I. \& Spyrou, P. (2006). How Students Conceive Function: A Triarchic Conceptual Semiotic Model of the Understanding of a Complex Concept. The Montana mathematics enthusiast. 3(2), 256-272.

[15] Hansson, Ö. (2006). Studying the Views of Preservice Teachers on the Concept of Function. Doctoral Dissertation, Luleå university of Technology. Retrieved from http://www.diva-portal.org/smash/get/diva2:990531/FULLTEXT01.pdf

[16] Lambertus, A.J. (2007). Students' Understanding of the Function Concept: Concept Images and Concept Definitions. Master's Thesis, North Carolina State University. Retrieved from https://repository.lib.ncsu.edu/bitstream/handle/1840.16/2510/etd.pdf?sequence=1\&isAllowed=y

[17] Nguyen, G. \& Tran, N. (2014). Students Understanding of Function Concepts I K-16: Consistency and Misconceptions. Retrieved from www.researchgate.net/publication/276026804

[18] Sfard, A. (1991). On the Dual Nature of Mathematical Conceptions: Reflections on Processes and Objects as Different Sides of the Same Coin. Educational studies in mathematics. 22(1), 1-36.

[19] Sierpinska, A. (1992). On Understanding the Notion of Function. In E. Dubinsky and G. Harel (eds.), The Concept of Function: Aspects of Epistemology and Pedagogy (pp. 25-58). Retrieved from www.researchgate.net/publication/238287243

[20] Slavit, D. (1997). An Alternate Route to the Reification of Function. Educational Studies in Mathematics. 33(3), 259-281. 
[21] Tall, D. and Vinner, S. (1981). Concept Image and Concept Definition in Mathematics with Particular Reference to Limits and Continuity. Educational studies in Mathematics. 12, 151-169.

[22] Thomas, M. O. J. (2008). Conceptual Representations and Versatile Mathematical Thinking. In Proceedings of ICMI (Vol. 10). Retrieved from https://www.researchgate.net/publication/236131562।

[23] Vinner, S. (1983). Concept Definition, Concept Image, and the Notion of Function. International Journal of Mathematics Education in Science and Technology. 14(3), 293-305.

[24] Vinner, S. \& Dreyfus, T. (1989). Images and Definitions for the Concept of Function. Journal for Research in Mathematics Education. 20(4), 356-366.

*Corresponding author.

E-mail address: ashebir145@ gmail.com 